\title{
Evaluation of Hot Corrosion Properties for Nano-coated Superalloy
}

\author{
*14abbas Khammas Hussein, ${ }^{2}$ Thear Tarish, Abdul Raidha, ${ }^{2}$ Ali Mohsen Khudair
}

${ }^{1}$ Nanotechnology and Advance Materials Research Center, University of Technology, Baghdad, Iraq

${ }^{2}$ State Company for Electrical \& Electronic Industries, Ministry of Industry and Minerals, Iraq

\begin{tabular}{l} 
Article information \\
\hline Article history: \\
Received: March, 27, 2021 \\
Accepted: April, 17,2021 \\
Available online: April, 26, 2021 \\
\hline Keywords: \\
Composite desirability \\
K417G \\
Pack Cementation \\
Taguchi Method \\
\hline
\end{tabular}

Correspondence:

Abbas Khammas Hussein

130032@uotechnology.edu.iq

\begin{abstract}
The purpose of this study is to optimize the hot corroded pack coated Ni-based super alloy K417G using composite desirability. Pack cementation parameters optimization was performed using quality characteristics of diffusion coatings for pack cementation process, i.e. salt activator, Nano-powders master alloy powder and wt.\% Ge. Analysis of variance (ANOVA) was used for observing the most influencing pack cementation parameters on the quality characteristics, i.e. $\mathrm{Na}_{2} \mathrm{So}_{4}-6 \%$ wt. $\mathrm{V}_{2} \mathrm{O}_{5}$ (kp1), 100 wt $\% \mathrm{NaSO}_{4}\left(\mathrm{kp}_{2}\right)$, and 75 wt. $\% \mathrm{NaSO}_{4}-25$ wt $\% \mathrm{NaCl}\left(\mathrm{kp}_{3}\right)$. The optimal process parameters were calculated using composite desirability analysis, a confirmation test performed. Based on analysis of variance results, the wt.\% of Ge is the most significant controllable diffusion coating factor for the hot corroded pack coated $\mathrm{K} 417 \mathrm{G}$ at optimum setting conditions (A2, B1, C3) i.e. activator $(\mathrm{NaCl})$, master alloy $(90 \mathrm{Cr}-10 \mathrm{Al})$ and wt.\% of $\mathrm{Ge}(2 \%)$ according to the quality characteristics. Composite desirability was successfully applied on optimization of hot corroded pack coated $\mathrm{K} 417 \mathrm{G}$ using multi-performance characteristics.
\end{abstract}

DOI: 10.53293/jasn.2021.11208, Department of Applied Science, University of Technology

This is an open access article under the CC BY 4.0 license.

\section{Introduction}

High temperature coatings are used for protecting the high temperature components from environmental attack due to oxidation and hot corrosion. These coatings have been developed from simple aluminide coatings to complex overlay and duplex coatings. Aluminide coating were prepared using a pack cementation method. Pack cementation is one of the widely used surface coating technologies to economically improve high temperature oxidation and corrosion resistance of components [1]. Recently, the surface operating temperature of the K417 G Ni-base superalloy used in turbine blades has increased to $1200 \mathrm{C}^{\circ}$ and even more. High temperature has a big potential to degrade the surface of the components resulting in oxidation or corrosion which can shorten the life time of the components [2]. Many efforts have been undertaken to overcome this severe problem, one of them is by applying the aluminizing or chromizing coating to prevent the oxidation process on the surface of the components [3]. Aluminizing - chromizing diffusion coatings are widely used for high temperature oxidation and hot corrosion protection of turbine blades used in engine hot sections [2]. The pack cementation method is usually used for deposition of protective coatings on the protection against oxidation, corrosion and damage [4]. At high temperatures, $\mathrm{Al}$ and $\mathrm{Cr}$ in the coating are oxidized and form a thin $\mathrm{Al}_{2} \mathrm{O}_{3}$ and $\mathrm{Cr}_{2} \mathrm{O}_{3}$ scale, which works as the diffusion barrier and reduces the oxidizing speed of the 
base material. The coated elements are placed in the closed or half-closed containers and covered with mixture powder, which consists of metals used for deposition ( $\mathrm{Al}$ and $\mathrm{Cr}$ ), the halide activating agent and inactive filler. The coating is fabricated through the reduction of metal-halide vapors on the surface of base material followed by diffusion in the solid-state between the introduced metal and the substance [5].

The good repeatability of manufacturing process and low costs are the main advantages of the pack cementation method [6]. Generally, the pack cementation process can be classified into two types depending on its process temperature and the activity of deposition metal available in pack. They are high-temperature low-activity and lowtemperature high-activity[7]. Recently novel pack cementation coating with improved hot corrosion and oxidation resistance due to "reactive element effect"(REE)" produced using pack cementation method at low temperature on the substrate was developed [8]

In the present work the multi-objective methodology based-on Taguchi approach and composite desirability has been used for optimization of multiple parameters of coating with hot corroded of $\mathrm{K} 417 \mathrm{G}$ alloy. The outcome of this study will be used to explore the possible use of the developed coating for high temperature components.

\section{Experimental procedure}

The experimental work was performed by using sample of Ni-based super alloy K417G. The spectro-chemical analysis substrate material is reported in Table 1.

Table 1. Spectro-chemical analysis of K417G Alloy

\begin{tabular}{|c|c|c|c|c|c|c|c|c|}
\hline Ele. & $\mathrm{Cr}$ & $\mathrm{Co}$ & $\mathrm{Mo}$ & $\mathrm{Si}$ & $\mathrm{Y}$ & $\mathrm{Ti}$ & $\mathrm{Al}$ & $\mathrm{Ni}$ \\
\hline Wt. $\%$ & 8.8 & 10.1 & 2.9 & - & - & 3.93 & 5.7 & Bal. \\
\hline
\end{tabular}

Specimens with dimensions of approximately $20 \times 20 \times 5 \mathrm{~mm}$ were prepared. A hole of $2 \mathrm{~mm}$ in diameter was drilled in each sample in order to hang the sample in the thermos-balance by means of a platinum wire. All surfaces, including the edges were wet ground using 3201800 and 1200 grit silicon carbide papers.

Then, these samples were cleaned with water, degreased with acetone and ultrasonically cleaned for 20 min using ethanol as a medium. After drying, the samples were stored in polyethylene locked bags.

The pack powder mixture consisted of a $\mathrm{Cr}-\mathrm{Al}$ master-alloy, halide salt activator $\left(\mathrm{NH}_{4} \mathrm{Cl}, \mathrm{NaCl}\right.$ and $\left.\mathrm{NaF}\right)$ and aluminum powder as a filter. In selected packs some alumina was replaced by Ge Nano-powder (70 nm) which acted as a source of reactive element.

The sample was placed in a sealed stainless steel cylindrical retort of diameter around $50 \mathrm{~mm}$ and a height of $80 \mathrm{~mm}$ in contact with the pack mixture. Then, the crucible was put in another stainless steel crucible of $80 \mathrm{~mm}$ in diameter and $140 \mathrm{~mm}$ in height. The pack cementation process was conducted at $1150 \mathrm{C}^{\circ}$ for 7 hours in the pure Ar atmosphere. Schematic illustration of the coating process is shown in figure (1).

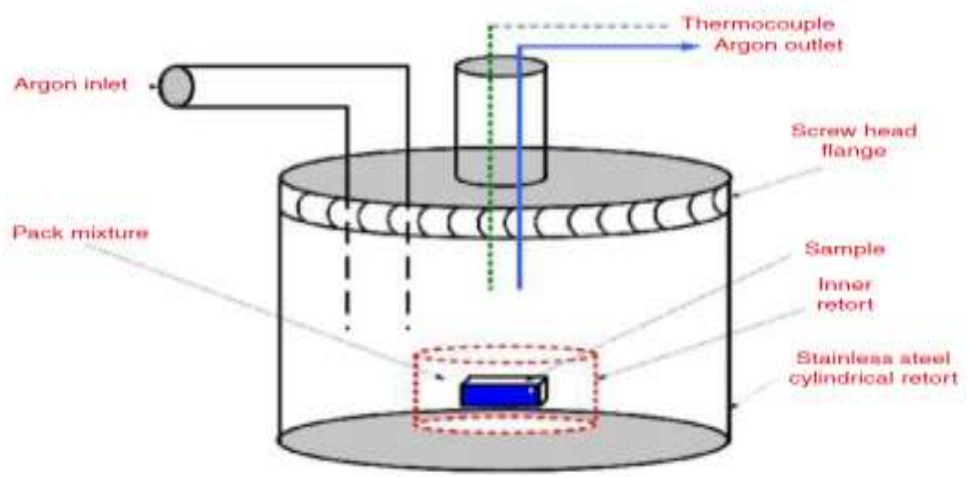

Figure 1. Pack Cementation Set-up 
Following the diffusion coating process, the samples were ultra-sonically cleaned and cut in perpendicular to the interface. Finally, the surfaces and cross sections were examined by scanning electron microscope (SEM) and X-ray diffraction (XRD). To characterize the surface and cross-sectional morphology of the coatings at optimum setting conditions.

Cyclic hot corrosion studies were performed in molten salts $\left(\mathrm{Na}_{2} \mathrm{So} 4, \mathrm{NaCl}\right.$ and $\left.\mathrm{V}_{2} \mathrm{O}_{5}\right)$ for 20 cycles, each cycle consisted of 5 hours heating at $700 \mathrm{C}^{\circ}$ in a programmable tube furnace specimens were deposited with each of these salts until a total coating weight of $5 \mathrm{mg} / \mathrm{cm}^{3}$ was reached. Salt coated specimens were then kept in the oven for 4 hours at $100 \mathrm{C}^{\circ}$. Then they were weighed again on a digital balance before exposing to hot corrosion tests in tube furnace.

The studies were conducted for all coated specimens. After testing the specimens, they were cleaned in an ultrasonic bath, first in distilled water and then in ethanol. Then they were weighed on a digital balance to determine the weight change. The parabolic rate constants $\left(\mathrm{K}_{\mathrm{p}}\right)$ of hot corrosion were calculated by linear least square algorithm of the following equation [9]:

$$
(\mathrm{W} / \mathrm{A})^{2}=\mathrm{K}_{\mathrm{Pt}}
$$

Where $(\mathrm{W} / \mathrm{A})=$ weight gain per unit area $\left(\mathrm{mg} / \mathrm{cm}^{2}\right)$, $\mathrm{t}=$ time of exposure (hour) and $\mathrm{kp}=$ parabolic rate constant (hot corrosion rate) $\left(\mathrm{mg}^{2} \mathrm{~cm}^{-4} \mathrm{~S}^{-1}\right)$. Many efforts were made to formulate the kinetics of hot corrosion- SEM and XRD techniques were used to analyze the hot corrosion products at optimum setting conditions.

Experiments of hot corrosion were conducted based on the design of experiments (DOE) using Taguchi method of three levels, each level with three factors $\left(\right.$ L9- $\left.3^{3}\right)$ as shown in Table 2.

Table 2. Taguchi-Array L9

\begin{tabular}{|c|c|c|}
\hline Activator(A) & $\begin{array}{c}\text { Master } \\
\text { Alloy(B) }\end{array}$ & $\begin{array}{c}\text { Wt.\% } \\
\text { Ge(C) }\end{array}$ \\
\hline $\mathrm{NH} 4 \mathrm{C} 1$ & $90 \mathrm{Cr}-10 \mathrm{Al}$ & 1 \\
\hline $\mathrm{NH} 4 \mathrm{C} 1$ & $2 \mathrm{Cr}-8 \mathrm{Al}$ & 1.5 \\
\hline $\mathrm{NH} 4 \mathrm{C} 1$ & $94 \mathrm{Cr}-6 \mathrm{Al}$ & 2 \\
\hline $\mathrm{NaCl}$ & $90 \mathrm{Cr}-10 \mathrm{Al}$ & 1.5 \\
\hline $\mathrm{NaCl}$ & $2 \mathrm{Cr}-8 \mathrm{Al}$ & 2 \\
\hline $\mathrm{NaCl}$ & $94 \mathrm{Cr}-6 \mathrm{Al}$ & 1 \\
\hline $\mathrm{NaF}$ & $90 \mathrm{Cr}-10 \mathrm{Al}$ & 2 \\
\hline $\mathrm{NaF}$ & $2 \mathrm{Cr}-8 \mathrm{Al}$ & 1 \\
\hline $\mathrm{NaF}$ & $94 \mathrm{Cr}-6 \mathrm{Al}$ & 1.5 \\
\hline
\end{tabular}

Taguchi orthogonal array- the values taken by a factor are termed to be levels. The Taguchi approach is more effective method than traditional design of experiment methods such as factorial design, which is resource and time consuming. It is correct to point out also the limitations of the Taguchi method. Most critical drawbacks of the Taguchi method is that it does not account higher order interactions between design parameters. Only main effects and two factor interactions are considered. Taguchi methods, developed by Dr.Genichi Taguchi, are based on the following two ideas[10]

1- Quality should be measured by the deviation from the specified target value rather than by conformance to present tolerance limits.

2- Quality cannot be ensured through inspection and rework, but must be built in through the appropriate design of the process and product in the Taguchi method, two factors such as the control factor and the noise factor are considered to study the influence of output parameters.

The controlling factors are used to select the best conditions for a process, whereas the noise factors denote all factors that cause variation. The following three parameters, were chosen for this study; halide salt activator (A), Nano- 
powders $(70 \mathrm{~nm})$ of master alloy (B), and weight percent of Ge nano-powder. The values or levels for the pack cementation parameters were determined according to thermodynamics mechanism and kinetics of the position of elements in diffusion coatings by the pack cementation method [7]. The parameters and their levels used in the experiments are shown in Table 3.

Table 3. Parameters and their levels used in the experiments

\begin{tabular}{|c|l|c|c|c|}
\hline Symbol & Control & \multicolumn{3}{|c|}{ Levels } \\
\cline { 3 - 5 } & \multirow{2}{*}{ Factor } & & \multicolumn{3}{|}{} \\
\cline { 3 - 5 } & & 1 & $\mathrm{NaCl}$ & $\mathrm{NaF}$ \\
\hline A & Activator & $\mathrm{NH} 4 \mathrm{Cl}$ & $92 \mathrm{Cr}-$ & $94 \mathrm{Cr}-$ \\
\hline B & Master & $90 \mathrm{Cr}-$ & $\mathrm{Al}$ & $6 \mathrm{Al}$ \\
\hline C & Alloy & $10 \mathrm{Al}$ & 1.5 & 2 \\
\hline
\end{tabular}

To evaluate the performance of pack cementation process, the following output characteristics were selected: parabolic rate constants $\left(\mathrm{Kp}_{1}\right)$ for hot corrosion coated Ni-based superalloy $\mathrm{K} 417 \mathrm{G}$ in molten salt environment, $\mathrm{Na}_{2} \mathrm{So}_{4}-6 \%$ wt. $\mathrm{V}_{2} \mathrm{O}_{5}(\mathrm{kp} 1), 100$ wt\% $\mathrm{NaSO}_{4}\left(\mathrm{kp}_{2}\right)$, and 75 wt. \% $\mathrm{NaSO}_{4}-25$ wt \% $\mathrm{NaCl}\left(\mathrm{kp}_{3}\right)$. Simplified multicharacteristics methodology based on Taguchi's approach and composite desirability used to optimize the performance of pack cementation coating.

\section{Results and discussion}

For process optimization, desirability approach is used. Desirability is a method of finding the operational conditions that provides the most desirable response value. For single response, each experimental result is converted into a scale of $[0,1]$ by calculating their desirability $(\mathrm{d})$, where 1 is highly desirable and 0 are lowest desirable value [11]. The maximum value of desirability is then chosen, and the factor setting corresponding to that maximum desirability value is selected as optimal combination of parameters. The response is scaled into desirability depending on the nature of response namely larger-the-better, smaller-the better, and nominal-the-better. They are explained individually as:

Larger-The-Better (LTB) The value of the estimated response is expected to be larger than a lower bound. For this response type, Eq 2 defines the individual desirability function:

$$
d_{i}(Y)_{i}= \begin{cases}0 & Y<L \\ \left(\frac{Y-L}{T-L}\right)^{r} & L \leq Y \leq T \\ 1 & Y>T\end{cases}
$$

Smaller-The-Better (STB), the value of the estimated response is expected to be smaller than an upper bound. So, for this response type, the individual desirability function is defined by Eq 3:

$$
d_{i}(Y)_{i}= \begin{cases}1 & Y<T \\ \left(\frac{U-Y}{U-T}\right)^{r} & T \leq Y \leq U \\ 0 & Y>U\end{cases}
$$

Nominal-The-Better (NTB) The value of the estimated response is expected to achieve a particular target value. With this response type, Eq 4 defines the individual desirability function:

$$
d_{i}\left(Y_{i}\right)= \begin{cases}0 & Y<L \\ \left(\frac{Y-L}{T-L}\right)^{r_{1}} & L \leq Y \leq T \\ \left(\frac{U-Y}{U-T}\right)^{r_{2}} & T \leq Y \leq U \\ 0 & Y>U\end{cases}
$$


Where $\mathrm{Y}$ is response, $\mathrm{U}$ is upper limit, $\mathrm{L}$ is lower limit, $\mathrm{T}$ is target value and $\mathrm{r}, \mathrm{r} 1, \mathrm{r} 2$ are weights. After calculating the individual desirability, overall desirability or composite desirability is calculated by using Eq 5:

$D=\left(d_{1} \times d_{2} \times d_{3} \times \cdots d_{n}\right)=\left(\prod_{i=1}^{n} d_{i}\right)^{1 / n}$

Where $\mathrm{D}$ is composite desirability, $\mathrm{d} 1 ; \mathrm{d} 2 ; \ldots ; \mathrm{dn}$ is maximum desirable values for different response and $\mathrm{n}$ is the number of response.

Hot corrosion kinetics can be monitored using weight change plots. The weight gain square $\left(\mathrm{mg}^{2} / \mathrm{cm}^{4}\right)$ vs time (number of cycles) plots were plotted to establish the rate law for the hot corrosion. These graphs have been plotted to know the hot corrosion kinetics of specimens subjected to cyclic hot corrosion in molten salt environment, $\mathrm{Na}_{2} \mathrm{SO}_{4}$, $\mathrm{V}_{2} \mathrm{O}_{5}$ and $\mathrm{NaCl}$ at $700{ }^{\circ} \mathrm{C}$. It is observed that the coating follows a nearly parabolic rate is low. The parabolic rate (hot corrosion rate) constant $\mathrm{kp}$ was calculated by a linear least square algorithm to function in the form (W/A) ${ }^{2}=$ $\mathrm{kpt}$. The values of parabolic rate constant $\mathrm{kp}$ are reported in Table 4. Lower the value of $\mathrm{kp}$, higher will be the hot corrosion resistant and vice versa.

Table 4. Parabolic rate constant (hot corrosion rate) $\mathrm{kp}\left(10^{-10} \mathrm{mg}^{2} \mathrm{~cm}^{-4} \mathrm{~s}^{-1}\right)$

\begin{tabular}{|c|c|c|c|}
\hline \multicolumn{4}{|c|}{ Parabolic rate constant (hot corrosion rate) $\mathrm{kp}\left(10^{-10} \mathrm{mg}^{2} \mathrm{~cm}^{-4} \mathrm{~s}^{-1}\right)$} \\
\hline Exp. No & $\mathrm{K}_{\mathrm{P} 1}$ & $\mathrm{~K}_{\mathrm{P} 2}$ & $\mathrm{~K}_{\mathrm{P} 3}$ \\
\hline 1 & 0.11 & 1.67 & 1.11 \\
\hline 2 & 0.24 & 1.43 & 1.01 \\
\hline 3 & 0.43 & 1.32 & 0.99 \\
\hline 4 & 1.01 & 1.82 & 0.11 \\
\hline 5 & 0.98 & 1.02 & 1.22 \\
\hline 6 & 0.87 & 1.05 & 0.88 \\
\hline 7 & 1.04 & 0.89 & 0.97 \\
\hline 8 & 0.98 & 0.87 & 1.22 \\
\hline 9 & 1.04 & 0.99 & 1.43 \\
\hline
\end{tabular}

However, the optimized factor setting (A2B1C3) for hot corroded pack coated Ni-based super alloy K417G with optimum (Parabolic rate constant (hot corrosion rate) $\mathrm{kp}\left(10^{-10} \mathrm{mg}^{2} \mathrm{~cm}^{-4} \mathrm{~s}^{-1}\right)$ (multi-responses) is shown in figure (2) . 


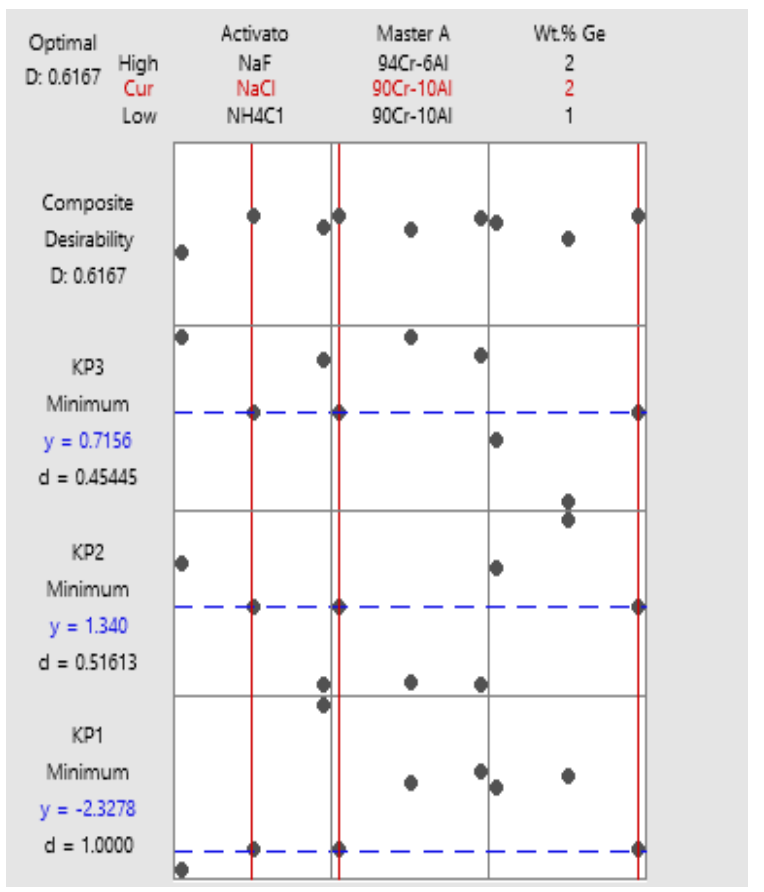

Figure 2. Optimized factor setting (A2B1C3) according to composite desirability

So (A2B1C3) as presented in figure (2) is the optimum parameters. The level with the maximum composite desirability is an optimal level of the process parameter. Analysis of variance (ANOVA) results for raw data of desirability results, is given in Table 5. It is seen that wt $\%$ Ge $(64 \%)$ significantly affect the hot corrosion rate as compared to halide salt activator $(20 \%)$ and master alloy powder $(16 \%)$.

Table 5. ANOVA Table for raw data.

\begin{tabular}{|l|l|c|c|c|}
\hline Parameter & DF & SS & MS & $\begin{array}{c}\text { Contribution } \\
\text { Ratio (\%) }\end{array}$ \\
\hline Halide salt activator & 2 & 0.02962 & 0.014806 & $20 \%$ \\
\hline Master alloy powder & 2 & 0.02426 & 0.012126 & $16 \%$ \\
\hline Wt.\% Ge & 2 & 0.09572 & 0.04786 & $64 \%$ \\
\hline
\end{tabular}

Confirmation tests are the final step recommended by composite desirability based on Taguchi approach to verify experiment conclusion. Estimated composite desirability is calculated as follows [15]:

$$
\gamma_{\text {opt }}=\gamma_{m}+\Sigma\left(\gamma_{i}-\gamma_{m}\right)
$$

Where $\gamma_{m}$ is the mean of single desirability, $\gamma_{i}$ is the mean of composite desirability at optimum level (A2B1C3), $\mathrm{i}$ is the number of process parameter having significant contribution in multiple performance characteristics. The summary results and comparison between experimental and predication results are shown in Table 6. Figure (3) shows the top-view morphology which is a thin oxide layer formed on the surface which mainly contains $(\mathrm{Cr}, \mathrm{Al}$ and $\mathrm{Ge})$, that are playing a significant role in a protection. So, According to XRD pattern, it is found that $\left(\mathrm{Cr}_{2} \mathrm{O}_{3}, \mathrm{Al}_{2} \mathrm{O}_{3}\right)$ oxides are mainly formed during hot corrosion and thus form a protective oxide layer at the surface due to which further hot corrosion is prevented and the presence of Ge (reactive element effect) improves the scale adhesion property and the scale formed is tightly adherent [16]. 

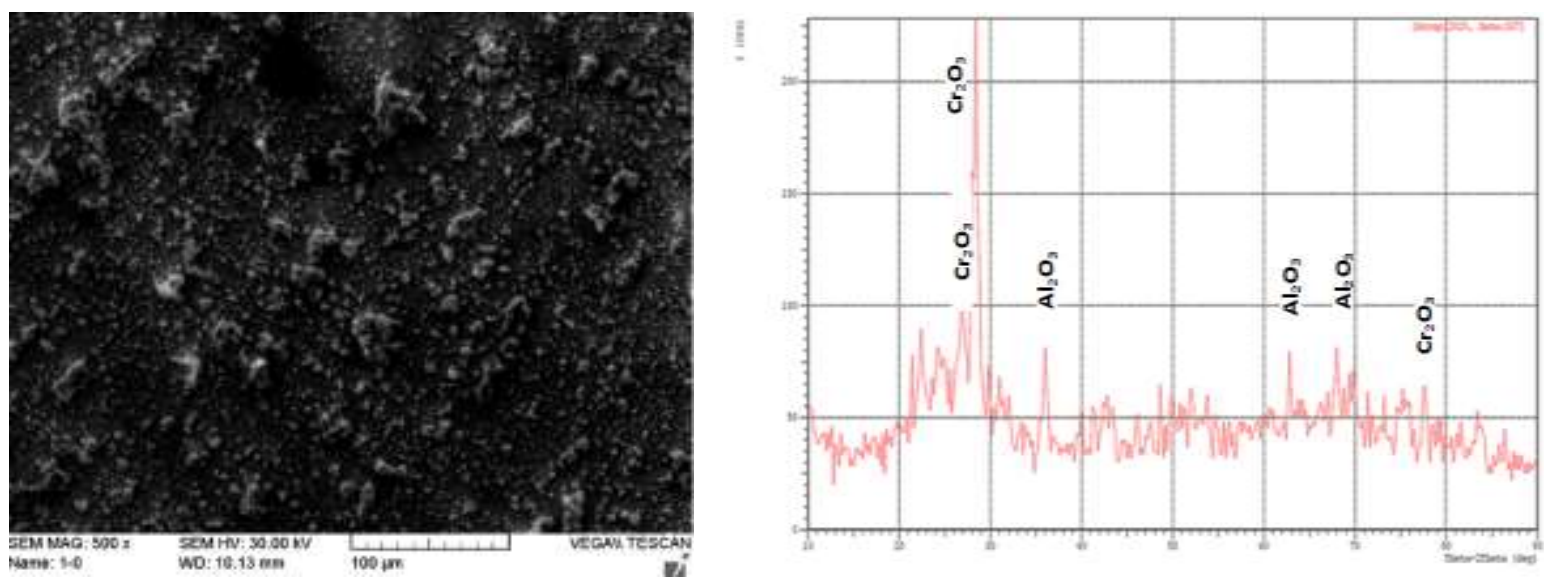

Figure 3. SEM/XRD Analysis for hot corroded pack coated K417G at optimum setting conditions (A2B1C3)

Table 6. Summary results of confirmation experiments

\begin{tabular}{|c|l|c|c|}
\hline method & level & \multicolumn{2}{|c|}{$\mathrm{K}_{\mathrm{p}}\left(10^{-10} \mathrm{mg} \mathrm{cm}^{4} \mathrm{~s}^{-1}\right)$} \\
\cline { 3 - 4 } & & experimental & Predication \\
\hline $\begin{array}{c}\text { Initial } \\
\text { condition }\end{array}$ & 111 & 0.981 & 1.011 \\
\hline $\begin{array}{c}\text { Optimal } \\
\text { condition }\end{array}$ & 213 & 0.598 & 0.6167 \\
\hline
\end{tabular}

\section{Conclusion}

The results acquired from this study can be drawn as follows:

1. According to grey relational analysis, the optimum parameters with composite desirability value of 0.6167 (closest to 1 is optimum) were $\mathrm{A} 2 \mathrm{~B} 3 \mathrm{C} 3$ i.e. Activator $(\mathrm{NaCl})$, master alloy $(90 \mathrm{Cr}-10 \mathrm{Al})$ and wt. $\% \mathrm{Ge}(2 \%)$.

2. According to the ANOVA results, wt. $\%$ Ge $(64 \%)$ is the most significant controllable as compared to halide salt activator $(20 \%)$ and master alloy powder $(16 \%)$.

3. According to XRD pattern, it is found that $\left(\mathrm{Cr}_{2} \mathrm{O}_{3}, \mathrm{Al}_{2} \mathrm{O}_{3}\right)$ oxides are mainly formed during hot corrosion.

\section{References}

[1] R. Hejazi, "High Temperature Coatings For Industrial Gas Turbine Users,” Accessed: Aug. 02, 2020.

[2] R. Drevet, C. Petitjean, N. David, L. Aranda, D. Veys-Renaux, and P. Berthod, "Aluminizing by pack cementation to protect CoSb3 from oxidation," Mater. Chem. Phys., vol. 241, p. 122417, Feb. 2020, doi: 10.1016/j.matchemphys.2019.122417.

[3] A. Galerie, B. Pint, and D. Monceau, "High Temperature Coatings," Oxid. Met., vol. 81, no. 1, pp. 1-1, Feb. 2014, doi: 10.1007/s11085-013-9462-3.

[4] R. Sivakumar and B. L. Mordike, "High temperature coatings for gas turbine blades: A review," Surf. Coat. Technol., vol. 37, no. 2, pp. 139-160, Apr. 1989, doi: 10.1016/0257-8972(89)90099-6.

[5] M. Okazaki, "High-temperature strength of Ni-base superalloy coatings," Sci. Technol. Adv. Mater., vol. 2, no. 2, pp. 357-366, Jan. 2001, doi: 10.1016/S1468-6996(00)00022-X.

[6] R. Rapp, "Pack Cementation Aluminide Coatings on Superalloys: Codeposition of Cr and Reactive Elements (RE). Technical Report 1. Chromium and Reactive Element(RE)- Modified Aluminide Diffusion Coatings on 
Superalloys: Environmental Testing. Technical Report 2,”p. 115, Nov. 1992.

[7] H. Zahedi, F. Shahriari Nogorani, and M. Safari, "Microstructure Analysis of the Pack Cementation Aluminide Coatings Modified by CeO2 Addition," Met. Mater. Int., Oct. 2019, doi: 10.1007/s12540-019-00483-0.

[8] J. Maximilien N'Gandu-Muamba and R. Streiff, "The reactive element effect (R.E.E.) : a tentative classification," J. Phys. IV Colloq., vol. 03, no. C9, pp. C9-281-C9-290, 1993, doi: 10.1051/jp4:1993927.

[9] D. Chellaganesh, M. Adam Khan , J. T. Winowlin Jappes and S. Sathiyanarayanan "Cyclic Oxidation and Hot Corrosion Behavior of Nickel-Iron-Based Superalloy" High Temperature Materials and Processes Volume 37 Issue 2, 2018.

[10] R. H. Myers, A. I. Khuri, and G. Vining, "Response Surface Alternatives to the Taguchi Robust Parameter Design Approach," Am. Stat., vol. 46, no. 2, pp. 131-139, May 1992, doi: 10.1080/00031305.1992.10475869.

[11] Deming SN. Multiple-criteria optimization. J Chromatogr A. 1991;550:15-25. doi: 10.1016/s00219673(01)88527-7. [Google Scholar]

[12] Hendriks MM, De Boer JH, Smilde AK, Doornbos DA. Multicriteria decision making. Chemometr. Intell Lab Syst. 1992;16(3):175-191. doi: 10.1016/0169-7439(92)80036-4. [Google Scholar]

[13] Derringer G, Suich R. Simultaneous optimization of several response variables. J Quality Technol. 1980;12:214-219. [Google Scholar]

[14] Y. Kuo, T. Yang, and G.-W. Huang, "The use of grey relational analysis in solving multiple attribute decisionmaking problems," Comput. Ind. Eng., vol. 55, no. 1, pp. 80-93, Aug. 2008, doi: 10.1016/j.cie.2007.12.002.

[15] J. Dai, X. Liu, and F. Hu, "Research and Application for Grey Relational Analysis in Multigranularity Based on Normality Grey Number," The Scientific World Journal, Feb. 16, 2014.

[16] D. Ghosh, S. Mukherjee, S. Das, and S. K. Mitra, "Effect of yttria (Y2O3) coating for high temperature oxidation resistance of 9Cr-1Mo steel," Prot. Met. Phys. Chem. Surf., vol. 52, no. 4, pp. 737-743, Jul. 2016, doi: $10.1134 / \mathrm{S} 2070205116040122$. 